\title{
Functional Diversity and Traits Assembly Patterns of Benthic Macrofaunal Communities in the Southern North Sea
}

\author{
Mehdi Ghodrati Shojaei, Lars Gutow, Jennifer Dannheim, Hendrik \\ Pehlke and Thomas Brey
}

\begin{abstract}
The study of ecosystem functioning - the fluxes of energy and material through biotic and abiotic components of an ecosystem - is becoming increasingly important in benthic ecological research. We investigated the functional structure of macrozoobenthic communities at four long-term sampling sites in the southern North Sea using biological traits assigned to life history, morphological and behavioural characteristics. The "typical" species of the macrofaunal assemblages at the sampling sites was characterized by small to medium body size, infaunal burrowing life style, deposit feeding habit, omnivory diet type, short to medium life span, gonochoristic sexual differentiation, $<2$ years age at maturity, high fecundity, and planktotrophic development mode. Functional diversity differed significantly among the four sites. As part of the present study, trait information for $>330$ macrofaunal taxa have been compiled in a comprehensive database.
\end{abstract}

Keywords Functional diversity • Biological traits • Macrozoobenthos • North sea

\section{Introduction}

Distribution, abundance and community composition of the North Sea macrozoobenthos are strongly influenced by a variety of physical, chemical and biological factors (Bremner et al. 2006; Franke and Gutow 2004; Kröncke et al. 2004). Temperature, water depth, food supply and sediment type have been shown to have critical, though sometimes variable effects on macrofaunal distribution

\footnotetext{
M. Ghodrati Shojaei $(\bowtie) \cdot$ L. Gutow $\cdot$ J. Dannheim $\cdot$ H. Pehlke $\cdot$ T. Brey Alfred Wegener Institute Helmholtz Centre for Polar and Marine Research, Am Handelshafen 12, 27570 Bremerhaven, Germany

e-mail: Mehdi.Shojaei@awi.de
}

M. Ghodrati Shojaei

Department of Marine Biology, Faculty of Marine Science, Tarbiat Modares University,

Tehran, Iran 
(Dutertre et al. 2013; Hillebrand 2004; Posey et al. 1995). Additionally, biological interactions (e.g. competition, predation) among species influence the diversity of marine assemblages (Defeo and McLachlan 2005). Many benthic species constitute a food source for fish and other predators (Pinto 2011). Predatory fish may directly reduce epifaunal abundances while their effects on infaunal species may be limited (Schlacher and Wooldridge 1996).

Marine ecosystems are routinely subjected to a wide range of anthropogenic disturbances (Marques et al. 2009; van der Molen et al. 2013). Exposure to bottom trawling, aggregate extraction and pollution are responsible for alteration of bottom habitats and may contribute to changes in growth, mortality and recruitment rate of species (Bergman and Hup 1992; Dannheim et al. 2014; Worm et al. 2006). These changes have the potential to modify the structure and functioning of benthic communities (van der Linden et al. 2012; Worm et al. 2006).

Ecosystem functioning is a general concept that encompasses a variety of phenomena, including ecosystem processes (e.g. energy fluxes), properties (e.g. pools of carbon and organic matter) and services (e.g. human alimentation) as well as the resistance or resilience of these factors in response to fluctuating abiotic conditions (Bremner et al. 2006; Díaz et al. 2008; Hooper et al. 2005; Loreau et al. 2001; van der Linden et al. 2012). Ecosystem functioning mainly depends on traits or characteristics of the constituent functional groups of organisms (Snelgrove 1997). Traditional analytical procedures, which derive biodiversity and community structure from species abundance/biomass data, do not take into account functional features of species (van der Linden et al. 2012). However, functional diversity, i.e. the range and number of functional traits performed within an ecosystem (Diaz and Cabido 2001), is a useful indicator of ecosystem functioning (Hooper et al. 2005). Several methods based on species morphological and ecological traits have been proposed to describe and quantify functional diversity of benthic assemblages (Beche et al. 2006; Bremner et al. 2006; Pacheco et al. 2011; van der Molen et al. 2013). We used biological trait analysis (BTA) to explore the ecological functioning of benthic assemblages (Sigala et al. 2012; van der Linden et al. 2012) and to compare functional diversity across different assemblages. BTA combines quantitative structural data (e.g. abundance) with information on biological characteristics of the taxa (Shettleworth 2012) to functionally characterise species assemblages (Bremner et al. 2006). This method is suitable for analysing assemblage responses to environmental parameters (Paganelli et al. 2012; Shettleworth 2012). Hence, BTA provides a link between benthic assemblages, environment and ecosystem processes (Oug et al. 2012; Pacheco et al. 2011)

The objectives of this study were (a) to determine the dominant functional characteristics of the German Bight benthos and (b) to identify functional differences between benthic communities at different sites by comparing functional diversity. 


\section{Material and Methods}

A database was generated from a long-term macro-zoobenthos time series at four sites in the German Bight (Fig. 1). Benthos samples were collected each spring from 1981 to 2011 (i.e. "taxa by station" matrix). The sites covered the dominant sediment types $(\mathrm{FSd}=$ fine sand, $\mathrm{Slt}=$ silt, $\mathrm{SSd}=$ silty sand and $\mathrm{WB}=$ White Bank with silty sand in deeper waters) in the south-eastern North Sea with the corresponding typical benthic associations (Salzwedel et al. 1985). At each station and sampling date, five $0.1 \mathrm{~m}^{2}$ samples were taken with a van Veen grab. The samples were sieved over $0.5 \mathrm{~mm}$ mesh and fixed in $4 \%$ buffered formalin. Macro-zoobenthic organisms were identified to species level as far as possible, counted and weighed (wet weight). In total we identified 334 species belonging to 235 genera and 157 families, respectively. After computing average abundance $\left(\mathrm{N} / \mathrm{m}^{-2}\right)$ per sampling date and station from the five replicate samples, our basic data matrix consisted of 334 species $\times$ four stations $\times 31$ sampling dates. From these data, we computed average abundance per species and station over the complete sampling period (1981-2011).

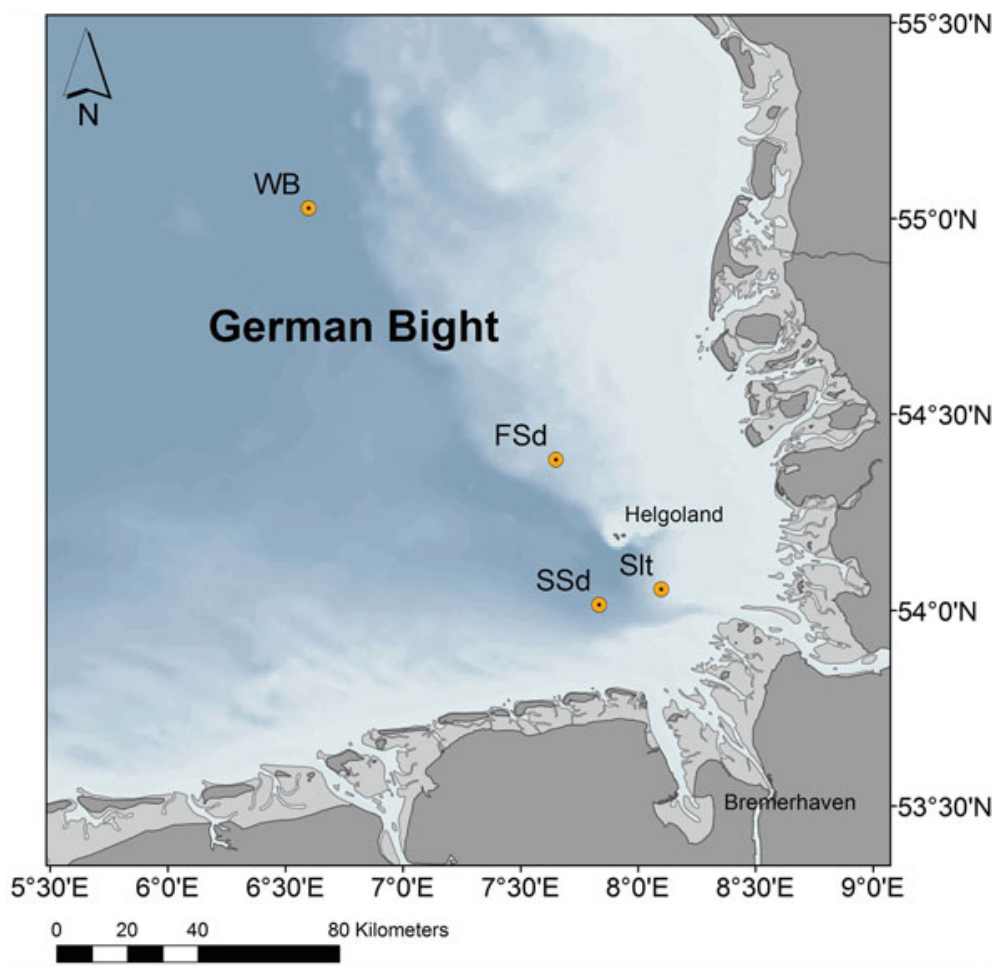

Fig. 1 Location of the four long-term monitoring sites (i.e. Slt silt; SSd silty sand, FSd fine sand, $W B$ White Bank) for macro-zoobenthos in the German Bight 
An autecological database (i.e. "trait by species" matrix) was generated from 10 different traits covering life history, behavioral characteristics, morphological attributes and environmental preferences of benthic species. Traits were selected either for their importance for the structure and functioning of the benthic system or for their sensitivity to changes in environmental variables. Each trait comprised qualitative or quantitative modalities, which allow for a functional characterization of individual taxa (Table 1). Specific trait modalities were assigned to individual taxa (i.e. species or genus) using a "fuzzy coding" procedure (Chevene et al. 1994) with a scoring range for affinities of zero to three. An affinity score of zero indicates no association of a taxon with a modality, whereas a score of three indicates highest affinity. For example, the polychaete Pisione remota mostly feeds as predator/ scavenger but may also feed occasionally as deposit feeder. Accordingly, the species was coded 1 for "surface/subsurface deposit feeder" and 2 for "predator/ scavenger" for the trait variable 'feeding habit'. Information on biological traits of taxa was compiled from peer-reviewed literature, species identification guides, online databases (e.g. BIOTIC 2012) and from personal expert consultations. Missing data were supplemented by using information referring to closely related species. To give the same weight to each taxon and trait, the scores were standardized by scaling the sum of all scores for each trait of a taxon equal to 100 . The standardized modality scores for each taxon were multiplied by the average species abundance at each station and summed up over all taxa. The results are a "trait by station matrix" providing the frequencies of occurrence of modalities in each year and at each station.

The complete trait dataset contained 10 traits subdivided into 43 modalities. The amount of information available differed markedly among traits. Information on feeding habit, environmental position and adult motility was abundant, whereas data on morphological traits (e.g. fragility) and fertilization type were not that readily available. The full data gathered on the species traits with an attributed reference list are available as Supplementary Material at PANGAEA - Network for Geological and Environmental Data (http://doi.pangaea.de/10.1594/PANGAEA.813419).

Functional diversity of an assemblage was calculated using the Quadratic entropy index (Rao 1982):

$$
F D_{R A O}=\sum_{i=1}^{s} \sum_{j=1}^{s} d_{i j} p_{i} p_{j}
$$

where $s$ is the number of taxa in the community and $p_{i}$ and $p_{j}$ are the proportion of the $i$ th and $j$ th taxon in the community, respectively. $d_{i j}$ is the trait dissimilarity between each pair of taxa $i$ and $j$ measured as Euclidean distance. Accordingly, $\mathrm{FD}_{\mathrm{RAO}}$ is the sum of the trait dissimilarities among all possible pairings of taxa, weighted by the relative abundance of the taxa (de Bello et al. 2009). FD RAO was calculated separately for each of the 11 biological traits and summed up for the entire assemblage of a site (Darr et al. 2014; van der Molen et al. 2013). FD RAO was calculated using the 'ADE-4' (Thioulouse et al. 1997) and 'VEGAN' libraries 
Table 1 Traits and their modalities used to assess functional composition

\begin{tabular}{|c|c|}
\hline Traits & Modalities \\
\hline \multirow[t]{8}{*}{ Feeding habit } & Surface deposit feeder \\
\hline & Sub-surface deposit feeder \\
\hline & Suspension feeder \\
\hline & Interface feeder \\
\hline & Predator \\
\hline & Sand licker \\
\hline & Grazer \\
\hline & Parasite \\
\hline \multirow[t]{3}{*}{ Environmental position } & Epifauna \\
\hline & Infauna \\
\hline & Epizoic \\
\hline \multirow[t]{4}{*}{ Adult movement } & Swimmer \\
\hline & Crawler \\
\hline & Burrower \\
\hline & Sessile \\
\hline \multirow[t]{3}{*}{ Diet type } & Omnivore \\
\hline & Carnivore \\
\hline & Herbivore \\
\hline \multirow{3}{*}{ Larval development } & Direct \\
\hline & Lecithotrophic \\
\hline & Planktotrophic \\
\hline \multirow{3}{*}{ Sexual differentiation } & Gonochoric \\
\hline & $\begin{array}{l}\text { Synchronous } \\
\text { hermaphrodite }\end{array}$ \\
\hline & Sequential hermaphrodite \\
\hline \multirow{4}{*}{ Adult longevity (years) } & $<1$ \\
\hline & $1-2$ \\
\hline & $3-10$ \\
\hline & $10+$ \\
\hline \multirow[t]{4}{*}{ Age at maturity (years) } & $<1$ \\
\hline & $1-2$ \\
\hline & $3-4$ \\
\hline & $4+$ \\
\hline \multirow[t]{6}{*}{ Fecundity } & $1-10$ \\
\hline & $10-100$ \\
\hline & $100-1,000$ \\
\hline & $100-10,000$ \\
\hline & $10,000-1 \mathrm{~m}$ \\
\hline & $1 \mathrm{~m}+$ \\
\hline
\end{tabular}


Table 1 (continued)

\begin{tabular}{l|l}
\hline Traits & Modalities \\
\hline Maximum size of organism & $<1$ \\
\cline { 2 - 2 }$(\mathrm{cm})$ & $1-10$ \\
\cline { 2 - 2 } & $11-20$ \\
\cline { 2 - 2 } & $20+$ \\
\hline
\end{tabular}

(Oksanen et al. 2013) for the open-source R software, version 3.0.1 (R Development Core Team 2009). Similarity in $\beta$-diversity (i.e. the variability in species composition among sampling sites for a given area at a given spatial scale) among the sampling sites were tested using a test for homogeneity of multivariate dispersions (PERMDISP routine, Permanova+ add-on in Primer 6; Anderson et al. 2008). The test was conducted on the basis of species composition (presence/ absence) data in conjunction with compositional dissimilarity (i.e., Sorensen resemblance measures). Functional diversity was compared among sampling sites by means of a Monte-Carlo random permutation test (999 permutations). For each trait, the distribution of modalities was compared among the four sampling sites using contingency tables (Chi square tests).

\section{Results}

For each trait, the distribution of modalities differed significantly between the four sampling sites (each $p<0.001$; Fig. 2). All benthic assemblages were dominated by infaunal organisms (Fig. 2a) with small to medium body size (1-10 cm; Fig. 2b). Small individuals $(<1 \mathrm{~cm})$ occurred mainly at stations Slt and WB. Most individuals were burrowers while sessile species were rare in all assemblages (Fig. 2c). Omnivorous organisms dominated the benthos whereas the proportion of purely herbivorous individuals was generally low (Fig. 2d). The reproductive mode was mainly gonochoric with development through a planktotrophic larval stage (Fig. 2e, f). The majority of the animals reached maturity within 2 years (Fig. $2 g$ ) and only few species had a life expectancy of more than 10 years (Fig. 2h). Only the assemblage at station WB had a higher proportion of individuals with a longevity $>10$ years. Feeding types were more heterogeneously distributed (Fig. 2i). Deposite feeders and interface feeders were generally the most common feeding types. However, predators/scavengers were also common at all sites. Fecundity mainly ranged between 10 and $10^{6}$ ind. fem. $^{-1}$ (Fig. 2j). Only at station Slt a considerable proportion of the infaunal assemblage produced more than $10^{6}$ ind. fem. $^{-1}$ while only few individuals produced less than 100 ind. fem. ${ }^{-1}$ at all sites.

The average functional diversity of the benthic assemblages ranged from $\mathrm{FD}_{\mathrm{RAO}}=1.66 \pm 0.16$ at site Slt to $\mathrm{FD}_{\mathrm{RAO}}=2.01 \pm 0.06$ at site SSd. The functional diversity was significantly lower at site Slt than at all other sites $(p<0.001$; Fig. 3$)$. At site WB, the functional diversity was lower than at sites FSD and SSd $(p<0.01)$ which were not significantly different $(p>0.05)$. 
(a)

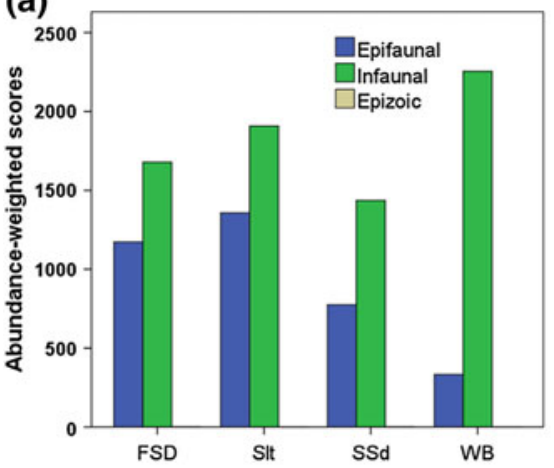

(c)

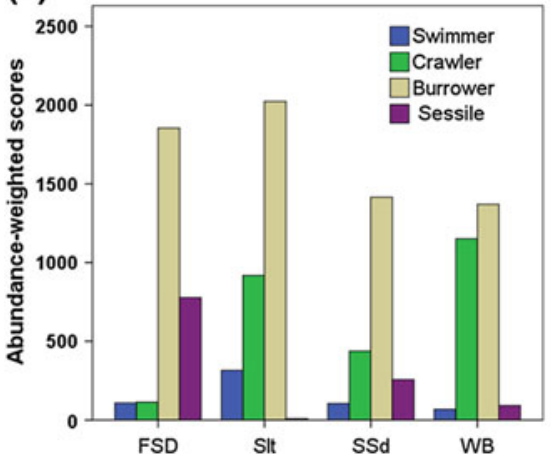

(e)

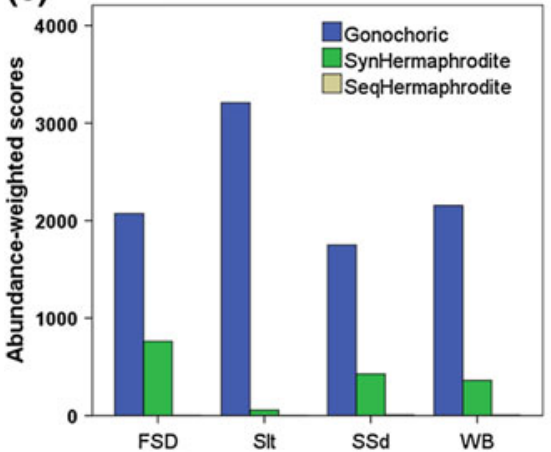

(b)

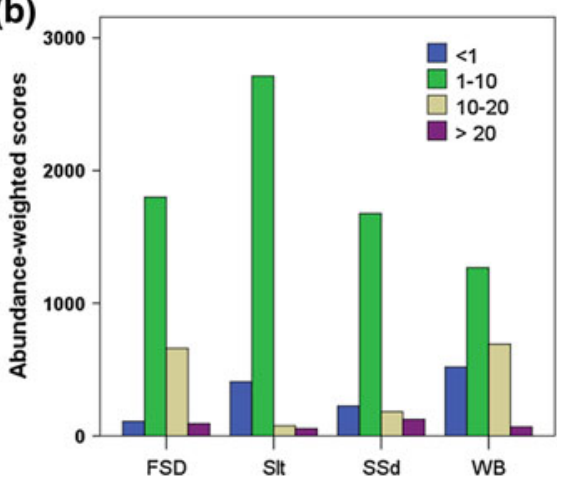

(d)

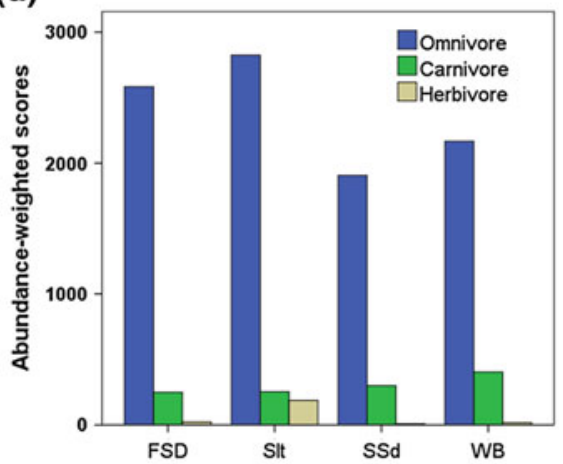

(f)

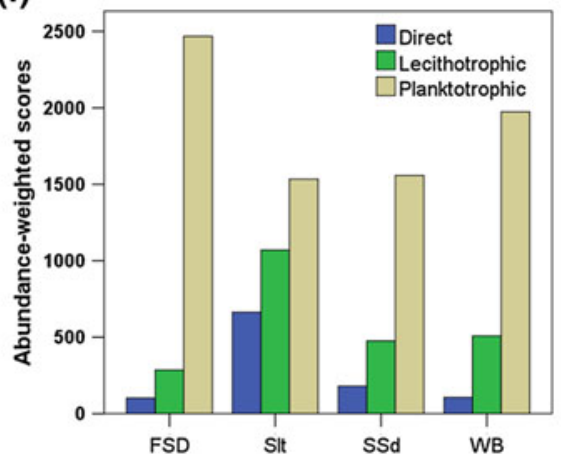

Fig. 2 Distribution of abundance-weighted modality scores (integrated over the entire 30 year period) within benthic infaunal assemblages at four sites in the German Bight: a environmental position, $\mathbf{b}$ size of organisms, $\mathbf{c}$ adult movement, $\mathbf{d}$ diet type, e sexual differentiation, $\mathbf{f}$ larval development, $\mathbf{g}$ age at maturity, $\mathbf{h}$ adult longevity, $\mathbf{i}$ feeding habit and $\mathbf{j}$ fecundity. Site names are FSd fine sand, Slt silt, SSd silty sand and WB White Bank. For each trait the distribution of modalities differed significantly between the four sampling sites $(p<0.001)$ 
(g)

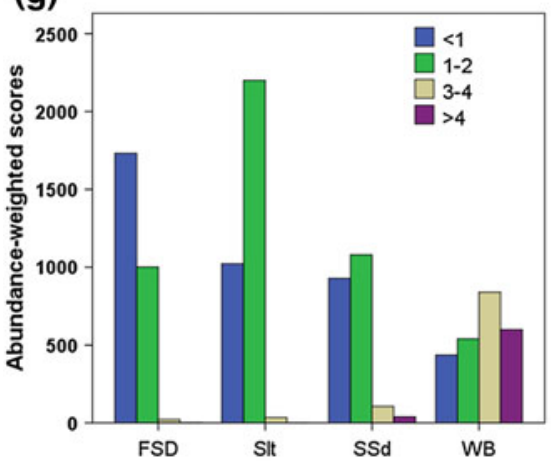

(i)

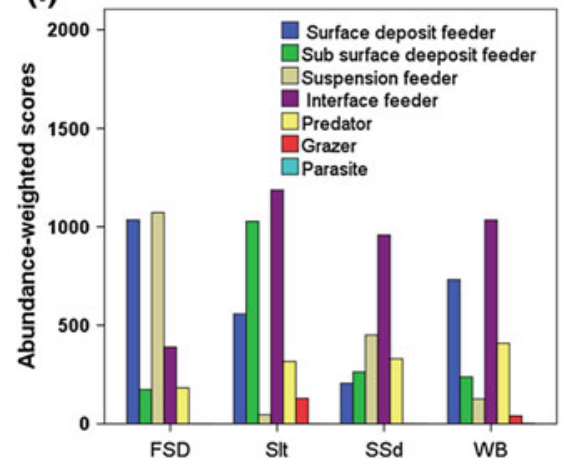

(h)

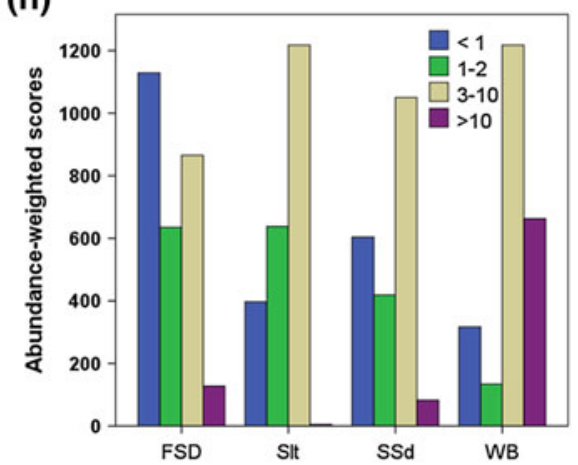

(j)

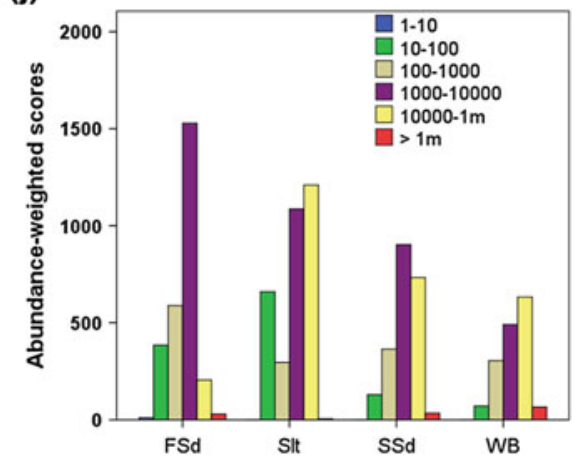

Fig. 2 (continued)

Fig. 3 Average $( \pm \mathrm{SD})$ functional diversity of the benthic infaunal communities at four sites in the German Bight. FSd fine sand, Slt silt, $S S d$ silty sand, WB White Bank

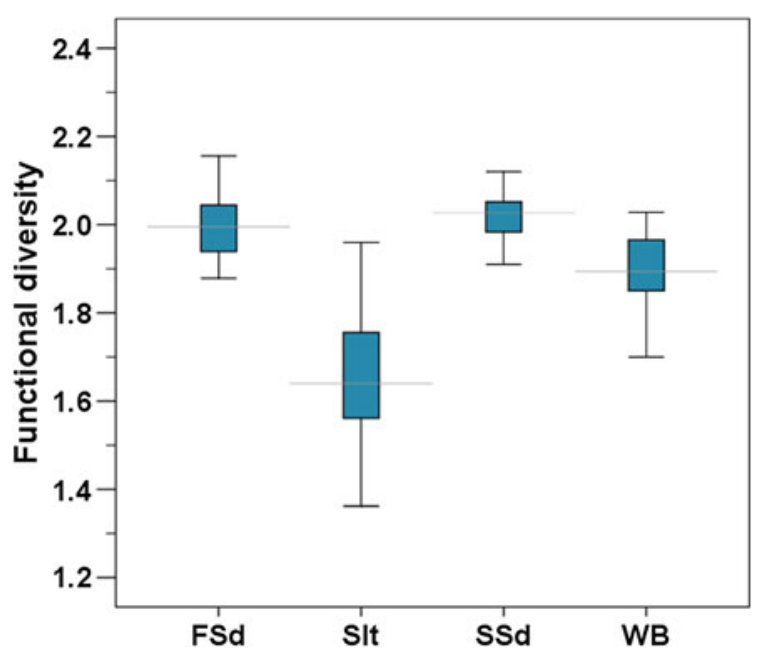




\section{Discussion}

The functional trait composition of the benthic assemblages in the German Bight indicates that the benthos of the south-eastern North Sea is generally dominated by small-sized and short-living opportunistic species. A dominance of opportunistic species is often characteristic for disturbed ecosystems (Borja et al. 2003; Thrush et al. 1998). In the North Sea various anthropogenic stressors (e.g. bottom trawling, eutrophication) have modified the benthic communities towards a suppression of large, long-living species, which were replaced by small, opportunistic species (Kaiser and Spencer 1996). For example, continuous physical disturbance of the seafloor by bottom trawling prevents the recovery of benthic species with multiannual life spans, low recruitment and slow post-recruitment development (Kroger 2003). These organisms are out-competed by opportunistic taxa with high recruitment rates and are, thus, at high risk of regional extinction (Calabretta and Oviatt 2008).

The test for homogeneity of multivariate dispersions revealed no differences among the three sampling sites (i.e. FSd, SSd and WB; $p>0.05$ ). Several environmental parameters may have contributed to the observed homogenization of benthic assemblages. However theoretical and empirical surveys have demonstrated that increased homogeneity mainly owing to anthropogenic and climatic disturbances (Passy and Blanchet 2007). Widespread anthropogenic and climatic pressures increase the harshness of habitat conditions and thus, reduce compositional heterogeneity among sites by decreasing the stochastic processes in structuring assemblages (Donohue et al. 2009; Olden and Poff 2004).

Pairwise test identified solely Slt as being significantly different $(p<0.01)$ from the other three sites in terms of variability in species composition. It is likely resulted from a lower species richness as well as from the numerical dominance of a few species (i.e., Nucula spp. and Owenia fusiformis constituted $>50 \%$ total benthic abundance). Numerical dominance of few species can be indicative of a highly stressed ecosystem (Méndez 2002). Slt was located in the innermost German Bight, in front of the mouths of the rivers Weser and Elbe. In addition to the role of the general large scale influences (e.g. bottom trawling) in the shaping of the entire German Bight ecosystem, it seems that some local scale drivers (e.g. river water run off), in particular, have caused drastic changes in the benthic assemblages at the Slt site. The possible effect of riverine discharge could be a function of the interaction between physical processes (e.g. sedimentation and advection) biological processes (e.g. losses via low-salinity intolerance) and chemical processes (e.g. nutrient enhancement) (Palmer et al. 2000). The functional trait composition were different among all four sampling sites (Fig. 2). For example, the benthic assemblage at the station WB showed a higher proportion of long-lived species suggesting more stable conditions and less disturbance in deeper offshore waters. Assembly theory for ecological communities suggests that two processes, i.e. competition and abiotic filtering (i.e. ecological filters that select individual taxa from a regional pool because they own a certain set of traits suitable for a given habitat (Díaz et al. 1998; 
Maire et al. 2012) affect the distribution of trait values within assemblages (Cornwell et al. 2006). Within a local community, competition aims to ecological differentiation of coexisting species, whereas abiotic filtering reduces the spread of trait values, reflecting common ecological tolerances (de Bello 2012; Kang et al. 2014).

The results also revealed that not only functional composition but also functional diversity differed significantly among sampling sites (Fig. 3). Spatial differences in functional diversity of benthic assemblages may emerge as a result of the environmental variation as well as distinct behaviors, processes and functions that are known to prevail in each ecosystem type (Dimitriadis et al. 2012; Levin et al. 2001). In conclusion, two important results can be deduced from our results: First, changes in benthic assemblages (e.g. homogenization of benthic assemblages in this study) are not necessarily linked with changes in ecological functions played by organisms. Second, biological traits analysis (BTA) is sensitive method in identifying differences among benthic assemblages and, thus, can provide additional information of community distribution patterns (Alves et al. 2014). For example, this method has proven to be a very useful approach for determining changes in benthic assemblages exposed to different disturbances such as bottom trawling (Tillin et al. 2006), marine aggregate dredging (Newell et al. 2004; Robinson et al. 2005) and eutrophication (Paganelli et al. 2012).

Acknowledgments We are deeply indebted to all the persons who contributed in the sampling, sample sorting and taxonomic identification. We thank the crew of all research vessels especially "FS Heincke" and "FS Uthörn" for their help with sampling throughout the years. The authors are also grateful for the very valuable comments of three anonymous reviewers. MSh is funded by the Iranian Ministry of Sciences, Research and Technology. We gratefully acknowledge partial support through Earth System Sciences Research School (ESSReS).

\section{References}

Alves A, Veríssimo H, Costa M, Marques J (2014) Taxonomic resolution and biological traits analysis (BTA) approaches in estuarine free-living nematodes. Estuar Coast Shelf Sci 138:6978

Anderson MJ, Gorley RN, Clarke KR (2008) PERMANOVA+ for primer: guide to software and statistical methods. PRIMER-E, Plymouth, p 214

Beche LA, Mcelravy EP, Resh VH (2006) Long term seasonal variation in the biological traits of benthic macroinvertebrates in two Mediterranean-climate streams in California, USA. Freshw Biol 51:56-75

Bergman M, Hup M (1992) Direct effects of beamtrawling on macrofauna in a sandy sediment in the southern North Sea. ICES J Mar Sci: J Conseil 49:5-11

Borja A, Muxika I, Franco J (2003) The application of a Marine Biotic Index to different impact sources affecting soft-bottom benthic communities along European coasts. Mar Pollut Bull 46:835-845

Bremner J, Rogers SI, Frid CLJ (2006) Matching biological traits to environmental conditions in marine benthic ecosystems. J Mar Syst 60:302-316 
Calabretta CJ, Oviatt CA (2008) The response of benthic macrofauna to anthropogenic stress in Narragansett Bay, Rhode Island: a review of human stressors and assessment of community conditions. Mar Pollut Bull 56:1680-1695

Chevene F, Doléadec S, Chessel D (1994) A fuzzy coding approach for the analysis of long-term ecological data. Freshw Biol 31:295-309

Cornwell WK, Schwilk DW, Ackerly DD (2006) A trait-based test for habitat filtering: convex hull volume. Ecology 87:1465-1471

Dannheim J, Brey T, Schröder A, Mintenbeck K, Knust R, Arntz WE (2014) Trophic look at softbottom communities - short-term effects of trawling cessation on benthos. J Sea Res 85:18-28

Darr A, Gogina M, Zettler ML (2014) Functional changes in benthic communities along a salinity gradient - a western Baltic case study. J Sea Res 85:315-324

de Bello F (2012) The quest for trait convergence and divergence in community assembly: are null-models the magic wand? Glob Ecol Biogeogr 21:312-317

de Bello F, Thuiller W, Lepš J, Choler P, Clément JC, Macek P, Sebastià MT, Lavorel S (2009) Partitioning of functional diversity reveals the scale and extent of trait convergence and divergence. J Veg Sci 20:475-486

Defeo O, McLachlan A (2005) Patterns, processes and regulatory mechanisms in sandy beach macrofauna: a multi-scale analysis. Mar Ecol Prog Ser 295:1-20

Díaz S, Cabido M (2001) Vive la difference: plant functional diversity matters to ecosystem processes. Trends Ecol Evol 16:646-655

Díaz S, Cabido M, Casanoves F (1998) Plant functional traits and environmental filters at a regional scale. J Veg Sci 9:113-122

Díaz AM, Alonso MLS, Gutiérrez MRVA (2008) Biological traits of stream macroinvertebrates from a semi-arid catchment: patterns along complex environmental gradients. Freshw Biol 53:1-21

Dimitriadis C, Evagelopoulos A, Koutsoubas D (2012) Functional diversity and redundancy of soft bottom communities in brackish waters areas: local vs regional effects. J Exp Mar Biol Ecol 426:53-59

Donohue I, Jackson AL, Pusch MT, Irvine K (2009) Nutrient enrichment homogenizes lake benthic assemblages at local and regional scales. Ecology 90:3470-3477

Dutertre M, Hamon D, Chevalier C, Ehrhold A (2013) The use of the relationships between environmental factors and benthic macrofaunal distribution in the establishment of a baseline for coastal management. ICES J Mar Sci: J Conseil 70:294-308

Franke H-D, Gutow L (2004) Long-term changes in the macrozoobenthos around the rocky island of Helgoland (German Bight, North Sea). Helgol Mar Res 58:303-310

Hillebrand H (2004) Strength, slope and variability of marine latitudinal gradients. Mar Ecol Prog Ser 273:251-267

Hooper D, Chapin F, Ewel J, Hector A, Inchausti P, Lavorel S, Lawton J, Lodge D, Loreau M, Naeem S (2005) Effects of biodiversity on ecosystem functioning: a consensus of current knowledge. Ecol Monogr 75:3-35

Kaiser MJ, Spencer BE (1996) The effects of beam-trawl disturbance on infaunal communities in different habitats. J Anim Ecol pp 348-358

Kang M, Chang SX, Yan ER, Wang XH (2014) Trait variability differs between leaf and wood tissues across ecological scales in subtropical forests. J Veg Sci 25(3):703-714

Kroger K (2003) Recovery of subtidal benthic macroinvertebrate communities following natural and experimental disturbances. Victoria University of Wellington

Kröncke I, Stoeck T, Wieking G, Palojärvi A (2004) Relationship between structural and functional aspects of microbial and macrofaunal communities in different areas of the North Sea. Mar Ecol Prog Ser 282:13-31

Levin LA, Boesch DF, Covich A, Dahm C, Erséus C, Ewel KC, Kneib RT, Moldenke A, Palmer MA, Snelgrove P (2001) The function of marine critical transition zones and the importance of sediment biodiversity. Ecosystems 4:430-451 
Loreau M, Naeem S, Inchausti P, Bengtsson J, Grime J, Hector A, Hooper D, Huston M, Raffaelli D, Schmid B (2001) Biodiversity and ecosystem functioning: current knowledge and future challenges. Science 294:804-808

Maire V, Gross N, Börger L, Proulx R, Wirth C, Pontes LDS, Soussana JF, Louault F (2012) Habitat filtering and niche differentiation jointly explain species relative abundance within grassland communities along fertility and disturbance gradients. New Phytologist 196:497-509

Marques J, Basset A, Brey T, Elliott M (2009) The ecological sustainability trigon-a proposed conceptual framework for creating and testing management scenarios. Mar Pollut Bull 58:1773-1779

Méndez N (2002) Annelid assemblages in soft bottoms subjected to human impact in the Urías estuary (Sinaloa, Mexico). Oceanol Acta 25:139-147

Newell R, Seiderer L, Simpson N, Robinson J (2004) Impacts of marine aggregate dredging on benthic macrofauna off the south coast of the United Kingdom. J Coastal Res 115-125

Oksanen J, Blanchet FG, Kindt R, Oksanen MJ, Suggests M (2013) Package 'vegan'. Community ecology package, version 2, 0-0

Olden JD, Poff NL (2004) Ecological processes driving biotic homogenization: testing a mechanistic model using fish faunas. Ecology 85:1867-1875

Oug E, Fleddum A, Rygg B, Olsgard F (2012) Biological traits analyses in the study of pollution gradients and ecological functioning of marine soft bottom species assemblages in a fjord ecosystem. J Exp Mar Biol Ecol 432:94-105

Pacheco AS, González MT, Bremner J, Oliva M, Heilmayer O, Laudien J, Riascos JM (2011) Functional diversity of marine macrobenthic communities from sublittoral soft-sediment habitats off northern Chile. Helgol Mar Res 65:413-424

Paganelli D, Marchini A, Occhipinti-Ambrogi A (2012) Functional structure of marine benthic assemblages using biological traits analysis (BTA): a study along the Emilia-Romagna coastline (Italy, North-West Adriatic Sea). Estuar Coast Shelf Sci 96:245-256

Palmer MA, Covich AP, Lake S, Biro P, Brooks JJ, Cole J, Dahm C, Gibert J, Goedkoop W, Martens K (2000) Linkages between aquatic sediment biota and life above sediments as potential drivers of biodiversity and ecological processes, a disruption or intensification of the direct and indirect chemical, physical, or biological interactions between aquatic sediment biota and biota living above the sediments may accelerate biodiversity loss and contribute to the degradation of aquatic and riparian habitats. Bioscience 50:1062-1075

Passy SI, Blanchet FG (2007) Algal communities in human-impacted stream ecosystems suffer beta-diversity decline. Divers Distrib 13:670-679

Pinto DFDBL (2011) Relationships between the structure of sublitoral assemblages and habitat complexity in a rocky shore in the Portugal coast

Posey M, Powell C, Cahoon L, Lindquist D (1995) Top down vs bottom up control of benthic community composition on an intertidal tideflat. J Exp Mar Biol Ecol 185:19-31

Rao CR (1982) Diversity and dissimilarity coefficients: a unified approach. Theor Popul Biol 21:24-43

R Development Core Team (2009) R: a language and environment for statistical computing. R Foundation for Statistical Computing, Viena. http://www.R-project.org

Robinson J, Newell R, Seiderer L, Simpson N (2005) Impacts of aggregate dredging on sediment composition and associated benthic fauna at an offshore dredge site in the southern North Sea. Mar Environ Res 60:51-68

Salzwedel H, Rachor E, Gerdes D (1985) Benthic macrofauna communities in the German Bight. Veröffentlichungen des Instituts für Meeresforschung Bremerhaven 20:199-267

Schlacher T, Wooldridge T (1996) Patterns of selective predation by juvenile, benthivorous fish on estuarine macrofauna. Mar Biol 125:241-247

Shettleworth SJ (2012) Do animals have insight, and what is insight anyway? Can J Exp Psychol 66:217-226

Sigala K, Reizopoulou S, Basset A, Nicolaidou A (2012) Functional diversity in three Mediterranean transitional water ecosystems. Estuar Coast Shelf Sci 110:202-209 
Snelgrove PV (1997) The importance of marine sediment biodiversity in ecosystem processes. Ambio 578-583

Thioulouse J, Chessel D, Dole S, Olivier J-M (1997) ADE-4: a multivariate analysis and graphical display software. Stat Comput 7:75-83

Thrush S, Hewitt J, Cummings V, Dayton P, Cryer M, Turner S, Funnell G, Budd R, Milburn C, Wilkinson M (1998) Disturbance of the marine benthic habitat by commercial fishing: impacts at the scale of the fishery. Ecol Appl 8:866-879

Tillin H, Hiddink J, Jennings S, Kaiser M (2006) Chronic bottom trawling alters the functional composition of benthic invertebrate communities on a sea-basin scale. Mar Ecol Prog Ser 318:31-45

van der Linden P, Patrício J, Marchini A, Cid N, Neto JM, Marques JC (2012) A biological trait approach to assess the functional composition of subtidal benthic communities in an estuarine ecosystem. Ecol Ind 20:121-133

van der Molen J, Aldridge JN, Coughlan C, Parker ER, Stephens D, Ruardij P (2013) Modelling marine ecosystem response to climate change and trawling in the North Sea. Biogeochemistry 113:213-236

Worm B, Barbier EB, Beaumont N, Duffy JE, Folke C, Halpern BS, Jackson JB, Lotze HK, Micheli F, Palumbi SR (2006) Impacts of biodiversity loss on ocean ecosystem services. Science 314:787-790 